Original Article

\title{
Work-related musculoskeletal disorders among occupational therapists in Korea
}

\author{
JuHyung PARK, MSc, OT ${ }^{1)}$ \\ 1) Department of Occupational Therapy, Kyungbuk College: 77 Daehakro, Yeongju-si, Gyengbuk \\ 750-712, Republic of Korea
}

\begin{abstract}
Purpose] The purpose of the study was to identify general characteristics of occupational therapists in Korea and to investigate the present conditions of their work-related musculoskeletal disorders (WRMD) in order to present preliminary data for its prevention and directions for improvement. [Subjects and Methods] This study was conducted by performing a survey about WRMD among 95 occupational therapists working in Korea. Frequency analysis was conducted for the work-related general characteristics of subjects and for parts of the body with musculoskeletal disorder, and a $\chi^{2}$ test was used to analyze the association between the presence of WRMD characteristics and each general characteristic. [Results] The parts of the body involved the most were the shoulders, hands, and neck (in decreasing order), and the work-related general characteristics shown to be associated with WRMD were the gender and the mean length of employment period. [Conclusion] The results of this study revealed that occupational therapists in Korea were extremely vulnerable to WRMD, and that realistic measures should be prepared swiftly for its prevention and treatment.
\end{abstract}

Key words: Musculoskeletal disorder, Musculoskeletal pain, Occupational therapists

(This article was submitted Jul. 29, 2015, and was accepted Aug. 30, 2015)

\section{INTRODUCTION}

Occupational therapy is a field of health and medical treatment that treats and educates people, whose physical, mental, or developmental function has been affected for some reason, through meaningful therapeutic activities to help them conduct daily activities as independently as possible as well as voluntarily participate in social activities so that they may lead satisfactory lives ${ }^{1}$. In addition, unlike practitioners in other medical services, occupational therapists are quite vulnerable to factors that can induce WRMD, because they have met patients face-to-face over a long period, and have to treat them through direct physical contact ${ }^{2}$.

Although research on WRMD has been actively conducted recently in various fields and types of occupations, the level of research conducted on WRMD among occupational therapists remains insignificant. Moreover, research on WRMD in physical therapists, who work in conditions similar to those of occupational therapists, is being extremely actively conducted; similar to physical therapists, who were found out to be extremely vulnerable to WRMD, occupational therapists are burdened with socio-psychological factors, biological dynamics factors, and factors related to

Corresponding author. JuHyung Park (E-mail: juhyungi79@ hanmail.net)

C2015 The Society of Physical Therapy Science. Published by IPEC Inc. This is an open-access article distributed under the terms of the Creative Commons Attribution Non-Commercial No Derivatives (by-ncnd) License $<$ http://creativecommons.org/licenses/by-nc-nd/3.0/>. harmful postures that can cause WRMD in their tasks and work environment ${ }^{3)}$. Therefore, this study aimed to identify general characteristics of occupational therapists in Korea and to investigate the present conditions of their WRMD in order to present preliminary data for its prevention and directions for improvement.

\section{SUBJECTS AND METHODS}

The study involved a self-administered questionnaire among 112 occupational therapists working in Korea. Of the 112 distributed questionnaires, a total of 101 were collected, and 95 were statistically analyzed after 6 that had imprecise responses were removed. This study was conducted after subjects provided written informed consent prior to participating in the study, in accordance with the ethical principles of the Declaration of Helsinki. The questionnaire used in Kim's study ${ }^{3)}$ on WRMD of physical therapists was used in this study after it had been modified and supplemented appropriately for occupational therapists, and the collected data was used to conduct a frequency analysis using SPSS version 17.0 (IBM Corporation) on work-related general characteristics of the subjects and the incidence of WRMD. In addition, a $\chi^{2}$ test was employed to determine associations between individual characteristics and WRMD incidence rates. When the expected frequency was less than 5 , the Fisher's exact test was applied. A value of 0.05 was set as the level of significance. 


\section{RESULTS}

The average age of all the respondents was 25.56 years, and the average length of their employment period was 32.17 months. There were more female respondents $(65.3 \%)$. Regarding the type of workplace, hospitals were the overwhelming majority at $92.6 \%$, and the major recipients of treatment were adult patients at $75.8 \%$. In addition, $81.1 \%$ of the respondents responded that they had no experience of receiving official education for preventing WRMD (Table 1). Occupational therapists reported that the shoulders $(81.1 \%)$ and the hands, wrists, or fingers $(73.7 \%)$ were the most common sites of pain when more than one answer was allowed (Table 2). The frequency of WRMD was associated with the gender $(\mathrm{p}=0.021)$ and employment period $(\mathrm{p}=0.01)$; it showed no relation to age $(\mathrm{p}=0.065)$, ergonomic training $(\mathrm{p}=0.218)$, type of workplace $(\mathrm{p}=0.214)$, or major recipients of treatment $(\mathrm{p}=0.381$; Table 3$)$.

Table 1. Work-related characteristics of occupational therapists

\begin{tabular}{|c|c|c|c|}
\hline \multicolumn{2}{|l|}{ 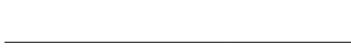 } & Mean \pm SD & Frequency $(\%)$ \\
\hline \multicolumn{2}{|l|}{ Age (years) } & $25.56 \pm 2.95$ & \\
\hline \multicolumn{2}{|c|}{ Work career (months) } & $32.17 \pm 22.85$ & \\
\hline \multirow{2}{*}{ Gender } & Male & & $33(34.7 \%)$ \\
\hline & Female & & $62(65.3 \%)$ \\
\hline \multirow{2}{*}{$\begin{array}{l}\text { Ergonomic train- } \\
\text { ing }\end{array}$} & Yes & & $18(18.9 \%)$ \\
\hline & No & & $77(81.1 \%)$ \\
\hline \multirow{2}{*}{$\begin{array}{l}\text { Type of work- } \\
\text { place }\end{array}$} & Hospital & & $88(92.6 \%)$ \\
\hline & Other & & $7(7.4 \%)$ \\
\hline \multirow{3}{*}{$\begin{array}{l}\text { Major recipients } \\
\text { of treatment }\end{array}$} & Adults & & $72(75.8 \%)$ \\
\hline & Children & & $21(22.1 \%)$ \\
\hline & Both & & $2(2.1 \%)$ \\
\hline
\end{tabular}

\section{DISCUSSION}

The purpose of the study was to identify general factors associated with occupational therapists in Korea and to investigate the present conditions influencing WRMD in order to present preliminary data for the prevention and directions for improvement. A comparison of the results of this study and the results of existing studies on musculoskeletal pain revealed that occupational therapists in Korea were younger, had shorter employment periods, and included more number of women compared to physical therapists who worked in similar working systems and environments ${ }^{4}$. In contrast to the results obtained from physical therapists, the results from occupational therapists revealed that they reported pain mainly in the shoulders and the hands ${ }^{5,6)}$.

These results suggest that the work-related musculoskeletal pain experienced by occupational therapists is caused by their nature of the work in that they use most of their time working using their shoulders and hands, including working with tools, helping patients perform exercises to improve their fine motor skills, and treating malfunctions of the upper limbs in order to improve the functions of patients with physical disabilities. The results of this study are similar to those of Kang's study on subjective musculoskeletal symptoms in occupational therapists and their related factors ${ }^{7}$. On analyzing the correlation between WRMD and the general characteristics of work-related occupational therapists, the gender and average employment period showed a significant correlation. First, the result about the gender is in line with the results of Chung's study, who reported that the gender could influence WRMD of physical therapists, and supports his argument on how males are physically more vulnerable to WRMD then females when conducting their medical tasks. ${ }^{4)}$ This study also showed a significant correlation between the average employment period and WRMD. When combined with the result that $81.1 \%$ of the subjects had responded that they had not received any education on preventing mus-

Table 2. Frequency of WRMD by body part

\begin{tabular}{llccccccc}
\hline & Neck & Shoulder & Arm/Elbow & $\begin{array}{c}\text { Hand/Wrist/ } \\
\text { Finger }\end{array}$ & Back & Hip/Thigh & Knee & Ankle/Foot \\
\hline $\mathrm{n}$ & 40 & 77 & 23 & 70 & 20 & 26 & 29 & 11 \\
$\%$ & 42.1 & 81.1 & 24.2 & 73.7 & 21.1 & 27.4 & 30.5 & 11.6 \\
\hline
\end{tabular}

WRMD: Work-related musculoskeletal disorder

Table 3. Distribution of WRMD by work-related characteristics

\begin{tabular}{|c|c|c|c|c|c|c|c|c|c|c|c|c|c|}
\hline & \multicolumn{2}{|c|}{ Age (years) } & \multicolumn{2}{|c|}{$\begin{array}{c}\text { Work career }{ }^{*} \\
\text { (months) }\end{array}$} & \multicolumn{2}{|c|}{ Gender ${ }^{*}$} & \multicolumn{2}{|c|}{$\begin{array}{l}\text { Ergonomic } \\
\text { training }\end{array}$} & \multicolumn{2}{|c|}{$\begin{array}{c}\text { Type of } \\
\text { workplace }\end{array}$} & \multicolumn{3}{|c|}{$\begin{array}{c}\text { Major recipients of } \\
\text { treatment }\end{array}$} \\
\hline & $<25$ & $\geq 25$ & $<33$ & $\geq 33$ & Male & Female & Yes & No & Hospital & Other & Adult & Children & Both \\
\hline $\begin{array}{l}\text { WRMD } \\
\text { n (\%) }\end{array}$ & $\begin{array}{c}37 \\
(38.9)\end{array}$ & $\begin{array}{c}46 \\
(48.4)\end{array}$ & $\begin{array}{c}45 \\
(47.3)\end{array}$ & $\begin{array}{c}38 \\
(40.0)\end{array}$ & $\begin{array}{c}25 \\
(26.3)\end{array}$ & $\begin{array}{c}58 \\
(61.0)\end{array}$ & $\begin{array}{c}13 \\
(13.6)\end{array}$ & $\begin{array}{c}70 \\
(73.6)\end{array}$ & $\begin{array}{c}78 \\
(82.1)\end{array}$ & $\begin{array}{c}5 \\
(5.2)\end{array}$ & $\begin{array}{c}61 \\
(64.2)\end{array}$ & $\begin{array}{c}20 \\
(21.0)\end{array}$ & $\begin{array}{c}2 \\
(2.1)\end{array}$ \\
\hline $\begin{array}{l}\text { NO WRMD } \\
\mathrm{n}(\%)\end{array}$ & $\begin{array}{c}9 \\
(9.4)\end{array}$ & $\begin{array}{c}3 \\
(3.1)\end{array}$ & $\begin{array}{c}12 \\
(12.6)\end{array}$ & $\begin{array}{c}0 \\
(0.0)\end{array}$ & $\begin{array}{c}8 \\
(8.4)\end{array}$ & $\begin{array}{c}4 \\
(4.2)\end{array}$ & $\begin{array}{c}4 \\
(4.2)\end{array}$ & $\begin{array}{c}8 \\
(8.4)\end{array}$ & $\begin{array}{c}10 \\
(10.5)\end{array}$ & $\begin{array}{c}2 \\
(2.1)\end{array}$ & $\begin{array}{c}11 \\
(11.5)\end{array}$ & $\begin{array}{c}1 \\
(1.0)\end{array}$ & $\begin{array}{c}0 \\
(0.0)\end{array}$ \\
\hline
\end{tabular}

WRMD: Work-related musculoskeletal disorder

*indicates significant association at $\alpha=0.05$ 
culoskeletal disorders, it can be considered that the social awareness about WRMD among occupational therapists in Korea and measures for its prevention are insignificant, and that the frequency of reporting pain increased as the average employment period lengthened. On analyzing the results of these studies, we understand that occupational therapists in Korea were exposed to many risk factors of WRMD, similar to physical therapists. Furthermore, occupational therapists included more female therapists who were vulnerable to WRMD, and their frequency of reporting pain increased as the employment period lengthened, because preventive measures or social awareness, such as carrying out preventive education, were extremely poor. Therefore, we believe that realistic measures for prevention and treatment should be prepared quickly in order to prevent and manage WRMD among occupational therapists in Korea.

The limitation of this study was the small sample size $(\mathrm{n}=$ 95), because of which diverse characteristics of occupational therapists could not be analyzed, thereby making it difficult to generalize the results of this study. In addition, the movements that could induce WRMD in clinical situations were not evaluated. Studies that are more systematic and detailed should be conducted by supplementing these limitations and utilizing analyzing tools for ergonomics.

\section{REFERENCES}

1) Yang YA, Hur JG, Noh YM, et al.: The study of job stress in occupational therapist. Journal of the Ergonomics Society of Korea, 2007, 26: 1-9. [CrossRef]

2) Park EY, Kim EJ: Job stress and self-efficacy of occupational therapist. J Korea Contents Assoc, 2008, 8: 208-216. [CrossRef]

3) Kim KM: Musculoskeletal pain and job stress of physical therapy. Yonsei University, Korea, 2005.

4) Chung SH, Her JG, Ko TS, et al.: Work-related musculoskeletal disorders among Korean physical therapists. J Phys Ther Sci, 2013, 25: 55-59. [CrossRef]

5) Cromie JE, Robertson VJ, Best MO: Work-related musculoskeletal disorders in physical therapists: prevalence, severity, risks, and responses. Phys Ther, 2000, 80: 336-351. [Medline]

6) Campo M, Weiser S, Koenig KL, et al.: Work-related musculoskeletal disorders in physical therapists: a prospective cohort study with 1-year follow-up. Phys Ther, 2008, 88: 608-619. [Medline] [CrossRef]

7) Kang MJ, Jeong WM, Koo JW: The factors related to musculoskeletal symptoms of occupational therapists. 2007, 15: 117-128 